\title{
Surgical treatment of left ventricular fibroma accompanied with ventricular septal defect in an infant: a case report
}

Yibo Gong, Ni Yin and Jinfu Yang ${ }^{*}$

\begin{abstract}
Primary cardiac tumor in infancy is an uncommon condition which is rarely accompanied with congenital heart disease. Although these tumors are generally benign, the complication associated with it, such as arrhythmia, outflow tract obstruction, and heart failure, may result in early mortality, when combined with congenital heart disease. Early surgical treatment may reduce complication risk and increase operative success rate which may improve the patient's long-term prognosis. Herein, we report a case of an eight-month-old Chinese baby boy diagnosed with a calcified fibroma combined with ventricular septal defect, the tumor excision and repair of ventricular septal defect were done at the same time.
\end{abstract}

Keywords: Congenital heart disease, Infant, Cardiac fibroma

\section{Background}

Primary cardiac tumors in infancy and childhood are uncommon, and approximately $70 \%$ of them are benign with morbidity rate of around $0.27 \%$ to $0.8 \%$. Most specialists advocate early individualized surgical resection to reduce mortality caused by complications such as heart inflow/ outflow tract obstruction, and malignant arrhythmia. Up to now, cardiac fibroma accompanied with VSD and $\mathrm{PH}$ has never been reported before, let alone simultaneous surgical treatment of both conditions.

\section{Case presentation}

An eight-month-old Chinese baby boy was admitted with a heart murmur suggestive of VSD. Echocardiogram revealed VSD and pulmonary hypertension (PH), the tumor was not detected until the operation. The patient subsequently underwent surgery under cardiopulmonary bypass (CPB). During the operation, the patient's pulmonary artery was noticeably dilated, and a perimembranous VSD approximately $16 \mathrm{~mm}$ in diameter was revealed. Further surgical exploration discovered a firm $4 \mathrm{~cm} \times 3.5 \mathrm{~cm} \times 3 \mathrm{~cm}$ mass with unclear-edges under the junction of the left anterior

\footnotetext{
* Correspondence: yjf19682005@sina.com

Department of the cardiothoracic surgery of the 2nd Xiangya Hosptial, Central South University, 410011 Changsha, China
}

descending (LAD) artery and the left circumflex (LCX) artery (Figure 1a). The mass was supplied by a large branch originating from LCX, and was adherent to surrounding tissues. Despite the mass being asymptomatic, there were concerns for the continued growth causing coronary artery compression and left ventricular cavity obstruction. These concerns were the reason for tumor resection at the time of VSD closure.

The VSD was repaired with a teflon patch. We opened the epicardium between LAD and LCX to expose the tumor and separate it from cardiac tissues, staying well away from the coronary arteries. We finally completely excised it from the left ventricle successfully (Figure 1b, c, d). Deciding on how to reconstruct the left ventricle was then considered. A patch repair may result in ventricular aneurysm which can lead to dyssynchronous contractility and subsequent decrease in cardiac function. The left ventricle was enlarged due to the volume overload on the left ventricle caused from the left to right shunt created by the VSD. As a result the myocardial tissue could be reapproximated easily to close the left ventricular wall defect. The patient was separated from $\mathrm{CPB}$ without any incidents. There was good left ventricular function with no compromise of the LAD and LCX (Figure 2). The patient was discharged on post-operative day 9 and remains asymptomatic on last follow-up. 


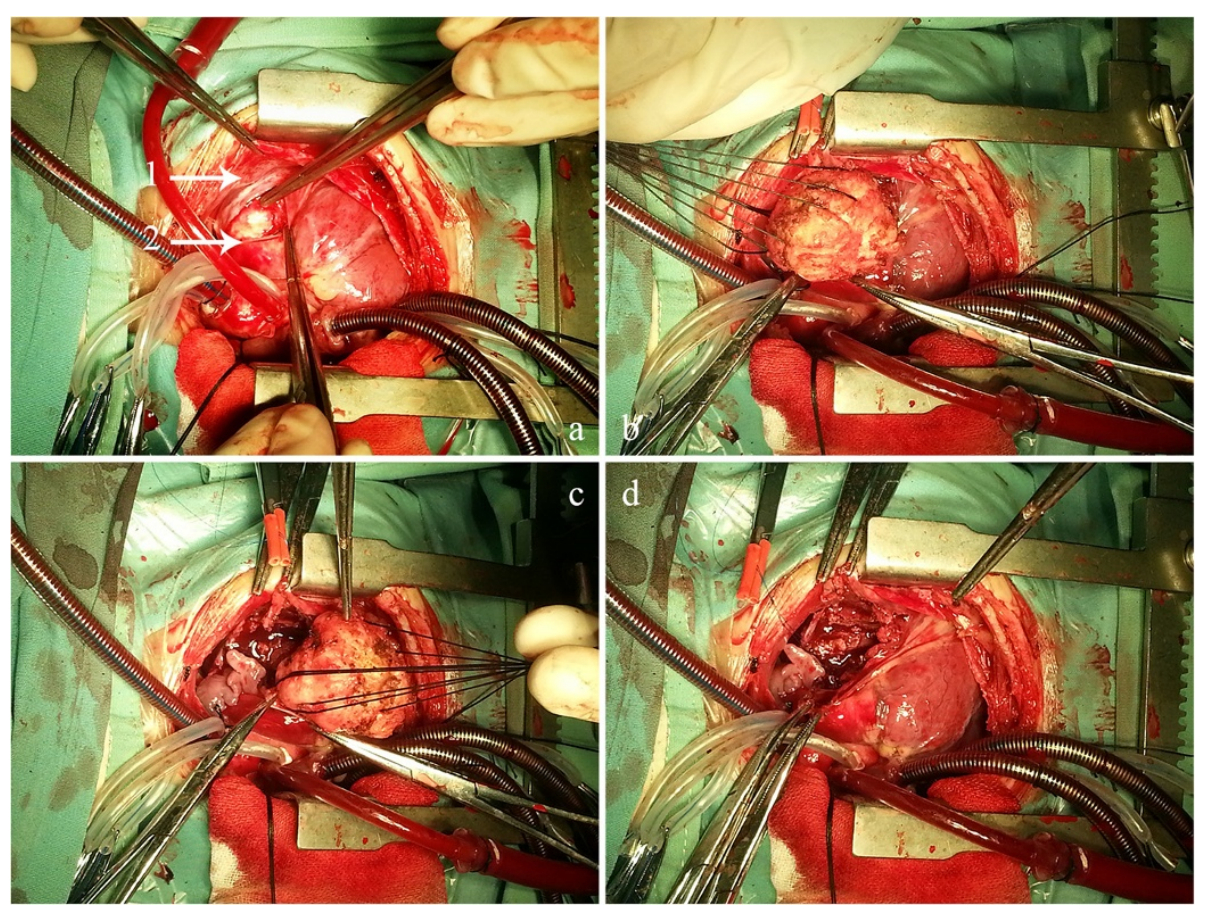

Figure 1 Surgical exploration reveals a firm $4 \mathrm{~cm} \times 3.5 \mathrm{~cm} \times 3 \mathrm{~cm}$ mass with unclear-edge under the LCX (1) and LAD (2). The cardiac mass, which was supplied by a large branch from LCX was surgically removed. 4 panels $(\mathbf{a}, \mathbf{b}, \mathbf{c}, \mathbf{d})$ show the whole process how the mass removed from LV.

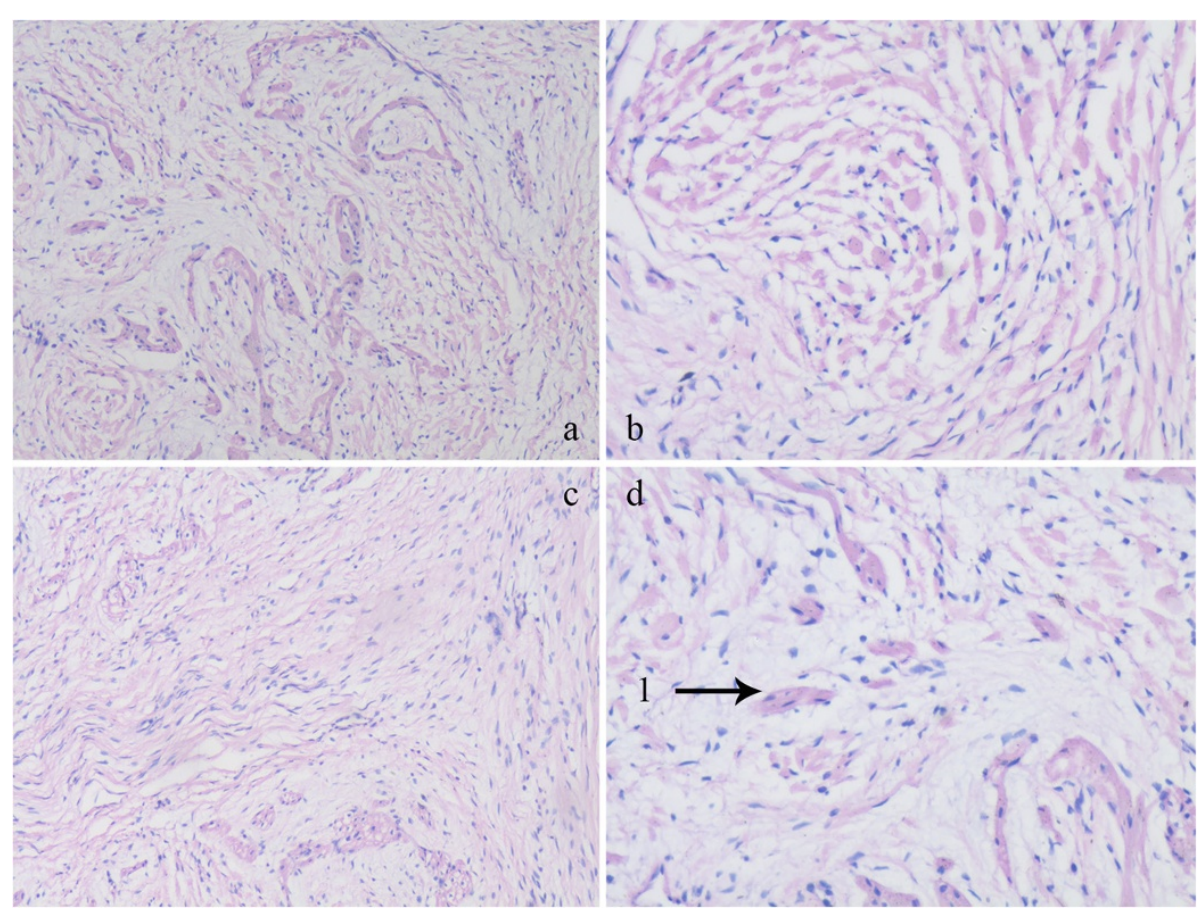

Figure 2 Pathological examinations of the removed mass report revealing calcifying fibroma (Armed by the arrow).

4 panels $(\mathbf{a}, \mathbf{b}, \mathbf{c}, \mathbf{d})$ show tumor tissue under microscope in different multiples and different position. The graphs which show normal tissue around the tumor also prompts the tumor has been completely resected. 


\section{Discussion}

Primary cardiac tumors in infancy and childhood are uncommon, and approximately $70 \%$ of them are benign with morbidity rate of around $0.27 \%$ to $0.8 \%$ [1]. Cardiac fibromas, which normally arise from heart fibroblasts or myofibroblast, accounts for around 2\% to $5 \%$ of all benign tumors in the heart [2]. Because of the complications such as heart inflow/outflow tract obstruction, and malignant arrhythmia associated prognosis of cardiac fibromas, many specialists advocate early individualized surgical resection [3-5]. Up to now, cardiac fibroma accompanied with VSD and $\mathrm{PH}$ has never been reported before, let alone simultaneous surgical treatment of both conditions. Left ventricular tumor excision combined with heart malformation correction is more complex than simple tumor excision because of prolonged CPB time, greater operation trauma.

\section{Conclusion}

Early tumor resection is recommended in such case to guarantee a successful surgical outcome with less potential complications. Secondly our experience showed that a combined surgical procedure to excise a cardiac tumor and repair a congenital heart defect is feasible and safe.

\section{Consent}

Written informed consent was obtained from the patient's parents for publication of this Case report and any accompanying images. A copy of the written consent is available for review by the Editor-in-Chief of this journal.

\section{Abbreviations}

CHD: Congenital heart disease; VSD: Ventricular septal defect; CPB: Cardiopulmonary bypass; LAD: Left anterior descending; LCX: The left circumflex; PH: Pulmonary hypertension.

\section{Competing interests}

The authors declare that they have no competing interests.

\section{Authors' contributions}

GYB participated in operation as an assistant and wrote the manuscript. NY managed the patient during operation period as attending doctor. JFY performed the surgery and supervised manuscript redaction. All authors read and approved the final manuscript.

\section{Acknowledgements}

We greatly appreciate the assistance of Muhoozi Rwakaryebe MD.

Received: 4 October 2013 Accepted: 17 February 2014

Published: 20 February 2014

\section{References}

1. Allen HD, Driscoll DJ, Shaddy RE, Feltes TF: In Moss and Adams' heart disease in infants, children, and adolescents: Including the fetus and young adult. 7th edition. Edited by FR DS. Philadelphia: Lippincott Williams \& Wilkins; 2007.

2. Burke A, Jeudy J Jr, Virmani R: Cardiac tumours: an update. Heart 2008, 94(1):117-123.

3. Horovitz A, van Geldorp IE, Roubertie F, Thambo J-B: Large right ventricular fibroma in a 6-month-old infant. Pediatr Cardiol 2012, 1-3.
4. Elahi M, Poh C-L, Krishna A, Grant P: Surgical considerations for large asymptomatic cardiac fibromas in the context of fatal ventricular arrhythmias. Heart, Lung and Circulation 2012, 21(11):750-753.

5. Torimitsu S, Nemoto T, Wakayama M, Okubo Y, Yokose T, Kitahara K, et al: Literature survey on epidemiology and pathology of cardiac fibroma. Eur J Med Res 2012, 17(1):5

doi:10.1186/1749-8090-9-37

Cite this article as: Gong et al:: Surgical treatment of left ventricular fibroma accompanied with ventricular septal defect in an infant: a case report. Journal of Cardiothoracic Surgery 2014 9:37.

\section{Submit your next manuscript to BioMed Central and take full advantage of:}

- Convenient online submission

- Thorough peer review

- No space constraints or color figure charges

- Immediate publication on acceptance

- Inclusion in PubMed, CAS, Scopus and Google Scholar

- Research which is freely available for redistribution 